Article

\title{
Sex-Specific Impact of Different Obesity/Metabolic Phenotypes on Long-Term Cardiovascular Outcomes in Acute Coronary Syndrome Patients
}

\author{
Egidio Imbalzano ${ }^{1,+} \oplus^{-}$, Giuseppina T. Russo ${ }^{1,+}$, Annalisa Giandalia ${ }^{1, *} \mathbb{C}$, Angela Sciacqua ${ }^{2}$, Luana Orlando ${ }^{1}$,

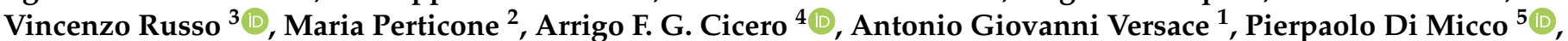 \\ Vincenzo Antonio Ciconte ${ }^{6}$, Giuseppe Dattilo ${ }^{1}$, Giovanni Squadrito ${ }^{1}$ and Marco Vatrano ${ }^{6}$ (i) \\ 1 Department of Clinical and Experimental Medicine, University of Messina, 98122 Messina, Italy; \\ egidio.imbalzano@unime.it (E.I.); giuseppina.russo@unime.it (G.T.R.); luana_orlando@libero.it (L.O.); \\ antonio.versace@polime.it (A.G.V.); giuseppe.dattilo@unime.it (G.D.); giovanni.squadrito@unime.it (G.S.) \\ 2 Department of Medical and Surgical Sciences, University Magna Græcia of Catanzaro, 88100 Catanzaro, Italy; \\ sciacqua@unicz.it (A.S.); mariaperticone@unicz.it (M.P.) \\ 3 Department of Medical Translational Sciences, Division of Cardiology, Monaldi Hospital, University of \\ Campania “Luigi Vanvitelli”, 80100 Naples, Italy; vincenzo.russo@unicampania.it \\ 4 IRCCS Policlinico S. Orsola-Malpighi, Hypertension and Cardiovascular Risk Research Center, DIMEC, \\ University of Bologna, 40126 Bologna, Italy; arrigo.cicero@unibo.it \\ 5 Department of Medicine, Buonconsiglio Fatebenefratelli Hospital, 80100 Naples, Italy; pdimicco@libero.it \\ 6 UTIC and Cardiology, Hospital "Pugliese-Ciaccio" of Catanzaro, 88100 Catanzaro, Italy; \\ vincenzo.ciconte@virgilio.it (V.A.C.); marco.vatrano1975@gmail.com (M.V.) \\ * Correspondence: agiandalia@yahoo.it \\ $\dagger$ These authors contributed equally to this work.
}

Citation: Imbalzano, E.; Russo, G.T.; Giandalia, A.; Sciacqua, A.; Orlando, L.; Russo, V.; Perticone, M.; Cicero, A.F.G.; Versace, A.G.; Di Micco, P.; et al. Sex-Specific Impact of Different Obesity/Metabolic Phenotypes on Long-Term Cardiovascular Outcomes in Acute Coronary Syndrome

Patients. Biomedicines 2022, 10, 424. https://doi.org/10.3390/

biomedicines10020424

Academic Editor: Celestino Sardu

Received: 7 December 2021

Accepted: 5 February 2022

Published: 10 February 2022

Publisher's Note: MDPI stays neutral with regard to jurisdictional claims in published maps and institutional affiliations.

Copyright: (c) 2022 by the authors. Licensee MDPI, Basel, Switzerland. This article is an open access article distributed under the terms and conditions of the Creative Commons Attribution (CC BY) license (https:// creativecommons.org/licenses/by/ $4.0 /)$.

\begin{abstract}
Obesity, a major risk factor for acute coronary syndrome (ACS), is a multifaceted disease with different metabolic phenotypes and sex-specific features. Here, we evaluated the long-term cardiovascular risk by different obesity/metabolic phenotypes and by sex in ACS patients. The occurrence of the composite outcome of death, nonfatal reinfarction with or without PCI and/or stroke was evaluated in 674 patients (504 men; 170 women), consecutively hospitalized for ACS and followed-up for 7 years, who were stratified in metabolically healthy (MHNW) and unhealthy normal weight (MUNW), and in metabolically healthy (MHO) and unhealthy obese (MUO) groups. At baseline, $54.6 \%$ of patients were included in the MHNW group, $26.4 \%$ in the MUNW, 5.9\% in the $\mathrm{MHO}$ and $13.1 \%$ in the MUO, with no sex-differences in the distribution of phenotypes. The overall rate of major outcome (100 person-years) in the reference group (MHNW) was higher in men than in women (RR: 1.19 vs. 0.6). The Kaplan-Meier curves for cumulative survival free from cardiovascular events according to obesity/metabolic status diverged significantly according to sex (log rank test, $p=0.006)$, this effect being more prominent in men $(\log 11.20 ; p=0.011)$, than in women $(\log 7.98$; $p=0.047$ ). Compared to MHNW, the risk increased in obese men (RR: $2.2 ; 95 \% 1.11-1.54$ in MUO group), whereas in women the risk was confined to metabolically unhealthy subjects (RR: 3.2; $95 \% \mathrm{CI}$ 1.23-9.98, MUNW group). Our data show a sex-specific impact of obesity phenotypes on long-term cardiovascular risk in patients hospitalized for ACS.
\end{abstract}

Keywords: sex; gender; acute coronary syndrome; metabolically healthy; obesity

\section{Introduction}

Obesity is a widely recognized risk factor for cardiovascular disease (CVD), morbidity and mortality [1]. Obesity also has adverse effects on metabolic factors, being a major component of metabolic syndrome (MetS) [2,3].

Current medical literature describes specific obesity phenotypes bearing different metabolic profiles and CVD risks. Thus, epidemiological studies have demonstrated that 
obesity free of metabolic abnormalities, i.e., individuals with the metabolic healthy obese (MHO) phenotype are at a lower CVD risk compared with metabolically unhealthy obese (MUO) ones [4]. However, not all data are concordant, and a recent study reported that the MHO phenotype may be associated with a higher risk of developing heart failure (HF), but not acute myocardial infarction (MI) [5].

Furthermore, an impaired metabolic profile associated with a normal weight was also demonstrated [4,5], suggesting the term of metabolically obese but normal weight (MONW) to describe individuals characterized by a higher susceptibility to type 2 diabetes (T2DM) and CVD, in spite of a normal weight [5]. This phenotype is not uncommon, and it seems to be associated with a high risk of all-cause and CVD mortality [5-7].

Up to date, the role of obesity on the CVD outcomes of subjects hospitalized for acute coronary syndrome (ACS) is still controversial, depending on the degree of obesity and on the length of follow-up, and data on the impact of different obesity phenotypes are even more sparse [8-10].

Moreover, sex-gender differences in obesity-related CVD outcomes may also play a role. Thus, obesity is more prevalent in women than in men worldwide, especially in low-income areas with a higher gender inequity gap [11,12]. Notably, sex/gender differences in the "obesity-lean paradox" on the risk of ACS recurrence have recently been demonstrated, with overweight ACS women showing the best prognosis [13]; furthermore, in ACS patients, significant interactions between gender-related variables and BMI on the 10-year prognosis were observed in females only [14].

These data suggest that cardiometabolic risk factors may be more strongly associated with adverse CVD outcomes than obesity per se [15], and that obesity-related phenotypes may differently impact the CVD risk in men and women.

In order to better clarify these issues in a very high risk population, in this prospective study we evaluated the impact of four obesity/metabolic phenotypes on the risk of the composite outcome of death, fatal or nonfatal reinfarction with or without PCI and/or stroke in a large cohort of ACS patients observed for 7 years, taking potential sex differences into account.

\section{Patients and Methods}

\subsection{Patients}

A sample of 674 patients (504 men; 170 women) consecutively hospitalized for acute coronary syndrome (ACS) in the cardiology and clinical and experimental medicine departments of Messina University Hospital and Hospital "Pugliese-Ciaccio" of Catanzaro, Italy, from January 2011 to January 2013 and followed up for 7 years was included in the current analysis. Patients were eligible if they met the criteria for ACS, proposed by the Joint European Society of Cardiology / American College of Cardiology Committee, and if they underwent immediate coronary revascularization procedures (primary PCI) for ST-elevation myocardial infarction (STEMI) or coronary revascularization procedures (early PCI) within $24 \mathrm{~h}$ for myocardial infarction without ST-elevation (nSTEMI) or diagnostic coronary angiography following coronary artery bypass graft surgery (CABG). Exclusion criteria were recognized coronary artery disease or previous ACS, PCI following CABG, cardiogenic shock, atrial fibrillation, peripheral artery disease, severe cardiac valve disease and the presence of a prosthetic aorta.

All participants were categorized into four groups, according to the presence or the absence of obesity and metabolic syndrome (MetS) as follows: metabolically healthy and normal weight (MHNW), metabolically unhealthy but normal weight (MUNW), metabolically healthy but obese (MHO) and metabolically unhealthy and obese (MUO). A written informed consent was obtained from each participant before initiating any study-related procedure. The study protocol was approved by the research review board of the participating hospital units. 


\subsection{Methods}

\subsubsection{Blood Pressure Measurements}

Clinical blood pressure (BP) readings were obtained in the supine position, after 5 min of quiet rest, with an aneroid sphygmomanometer. Systolic BP (SBP) and diastolic BP (DBP) were recorded at the first appearance (phase I) and the disappearance (phase V) of Korotkoff sounds, respectively. Baseline BP values were the average of three consecutive measurements obtained at intervals of $3 \mathrm{~min}$. Patients with clinical SBP $>140 \mathrm{mmHg}$ and/or DBP > $90 \mathrm{mmHg}$ were defined as hypertensive [2].

\subsubsection{Body Mass Index}

Height and weight were measured with participants wearing light clothes without shoes; height was measured to the nearest centimeter and weight was measured to the nearest half kilogram. BMI was calculated as body weight (kilograms) divided by the squared height (meters) and further subdivided into 2 categories: $<30 \mathrm{~kg} / \mathrm{m}^{2}$ (normal weight/nonobese overweight) and $>30 \mathrm{~kg} / \mathrm{m}^{2}$ (obese).

\subsubsection{Transthoracic Echocardiography (TTE)}

Examinations were performed by two independent observers who were unaware of the clinical data, evaluated the recordings and calculated the parameters. Images were taken with the patient in the left decubitus position using VIVID 7 ultrasound machines (GE Technologies, Milwaukee, WI, USA) with an annular $2.5 \mathrm{MHz}$ phased array transducer, as recommended by the American Society of Echocardiography [3].

\subsubsection{Metabolic Status}

Waist circumference was measured at the height of the umbilicus, and hip circumference was measured at the thickest part of the hip (in only 442 patients). Fasting serum samples were analyzed for glucose, triglycerides and high-density lipoprotein cholesterol. The time since last meal (in hours) was recorded. Information on previously diagnosed diabetes mellitus and the use of blood pressure medication was collected from the selfadministered questionnaire. We used a modified definition of metabolic health based on the MetS, as described by the International Diabetes Federation and MetS was defined according to an American Heart Association/National Heart, Lung, and Blood Institute Scientific Statement [16].

\subsubsection{Study Outcomes}

The primary measure of outcome was a composite of death, fatal or nonfatal reinfarction with or without PCI and/or stroke occurring during the 7 years of observation. Each CVD outcome was included as a specific secondary endpoint. Procedure-related AMI within $24 \mathrm{~h}$ was not included into the endpoint. Study participants were followed from the coronary revascularization at entry, until they experienced one of the primary endpoints, proven by hospitalization.

\subsection{Statistical Analysis}

Data are presented as means, standard deviations and frequency of occurrence (\%). Continuous variables were compared with the paired or unpaired Student's $t$-test, an ANOVA with a post hoc Tukey test, or with a simple Pearson correlation as appropriate. Discrete variables were compared using a Chi-squared analysis or a Fisher exact test. A test for normality was carried out on all variables using the Kolmogorov-Smirnov test, and non-normally distributed variables transformed for the purpose of the regression analysis. Furthermore, we calculated the relative risk ratio (RR) for $\mathrm{CV}$ events in patients with $\mathrm{BMI} \geq 30 \mathrm{~kg} / \mathrm{m}^{2}$ who were metabolically healthy or unhealthy, compared with normalweight/nonobese overweight patients $\left(\mathrm{BMI}<30 \mathrm{~kg} / \mathrm{m}^{2}\right)$ who were metabolically healthy (reference group). Incidence rates of $\mathrm{CV}$ recurrences were obtained by dividing the number of cases by person-years in each subgroup of metabolic phenotypes. Cox regression models 
were used to calculate the risk ratio between the incidence rate of CV events in metabolically healthy and unhealthy obesity subgroups divided by the incidence rate in the reference group. RR are presented as unadjusted, age- and sex-adjusted and multivariable-adjusted. Covariates in the multivariate-adjusted models were selected based on clinical relevance and when they increase $>10 \%$ the risk ratio. Furthermore, the difference in rates of CV events among groups, according to metabolic status categorization, during the followup period was assessed by the Kaplan-Meier method by means of the log-rank test. A $p$ value $<0.05$ was considered statistically significant. SPSS 20 statistical software was used for the analysis (Statistical Package for Social Sciences, Chicago, IL, USA).

\section{Results}

\subsection{Baseline Clinical Characteristics According to Sex}

Baseline clinical characteristics of the 674 subjects participating in the study (504 M, 170 F), according to sex and metabolic phenotypes are shown in Table 1. Overall, ACS women were older than men $(68.8$ vs. 62.4 years, $p<0.001)$ and they were less likely to be smokers (16.5 vs. $46 \%, p<0.001)$. Hypertension and T2DM were more frequent among women. Systolic blood pressure (SBP) values were higher in women than in men (146 mmHg vs. $141.3 \mathrm{mmHg}$ ) whereas diastolic blood pressure (DBP) values were similar in the two groups. Heart rate was also higher in women than in men (75.8 vs. 70.5 beats $/ \mathrm{min})$, while echocardiographic parameters, including ejection fraction (EF, mean value $53.8 \%$ ) and $\mathrm{E} / \mathrm{A}$ ratio (mean value 0.3 ) were similar in the two genders at baseline.

For the lipid profile, women had higher levels of HDL cholesterol (HDL-C) than men (48.6 vs. $43.7 \mathrm{mg} / \mathrm{dL}, p<0.001)$; total cholesterol (181.7 mg/dL), LDL cholesterol (LDL-C; $107.0 \mathrm{mg} / \mathrm{dL})$ and triglycerides levels $(146.5 \mathrm{mg} / \mathrm{dL})$ were not different in men and women. Women also presented higher levels of fasting blood glucose (FBG, 133.9 vs. $123.9 \mathrm{mg} / \mathrm{dL}$, $p=0.058)$. Creatinine $(1.0 \mathrm{mg} / \mathrm{dL})$ and C-reactive protein (CRP) levels (10.5) did not differ in the two genders.

No sex differences were noted in cardiovascular therapies, including users of antiplatelet (99.5\%), statin (99.3), diuretic (97.4\%), ACE inhibitor (97.4\%) and beta-blocker drugs, that were similar in ACS men and women.

Moreover, the extent of coronary artery disease (CAD), as assessed by the number of vessels affected by coronary disease (one- or two- or three-vessel disease), and the type of coronary revascularization procedure (single drug-eluting stent, multiple drug-eluting stents with overlapping, coronary artery bypass graft surgery) were comparable between men and women participating in the study.

\subsection{Baseline Clinical Characteristics According to Obesity-Related Phenotypes}

Study subjects were stratified into four phenotypes, according to BMI and the presence of MetS. Of the 674 enrolled ACS patients, 368 subjects (54.6\%), with baseline BMI values $<30 \mathrm{~kg} / \mathrm{m}^{2}$, were included in the MHNW subgroup, and 178 subjects (26.4\%) in the MUNW. Among those with BMI values $\geq 30 \mathrm{~kg} / \mathrm{m}^{2}, 40$ subjects $(5,9 \%)$ were included in the MHO and $88(13.1 \%)$ in the MUO group (Table 1$)$.

Table 1 shows the baseline clinical characteristics analyzed according to obesity/metabolic phenotypes. No difference in age, echocardiographic parameters (EF and E/A), heart rate, type of coronary revascularization and pharmacological therapy were noted among the study groups. 
Table 1. Study variables at baseline according to sex and metabolic phenotypes.

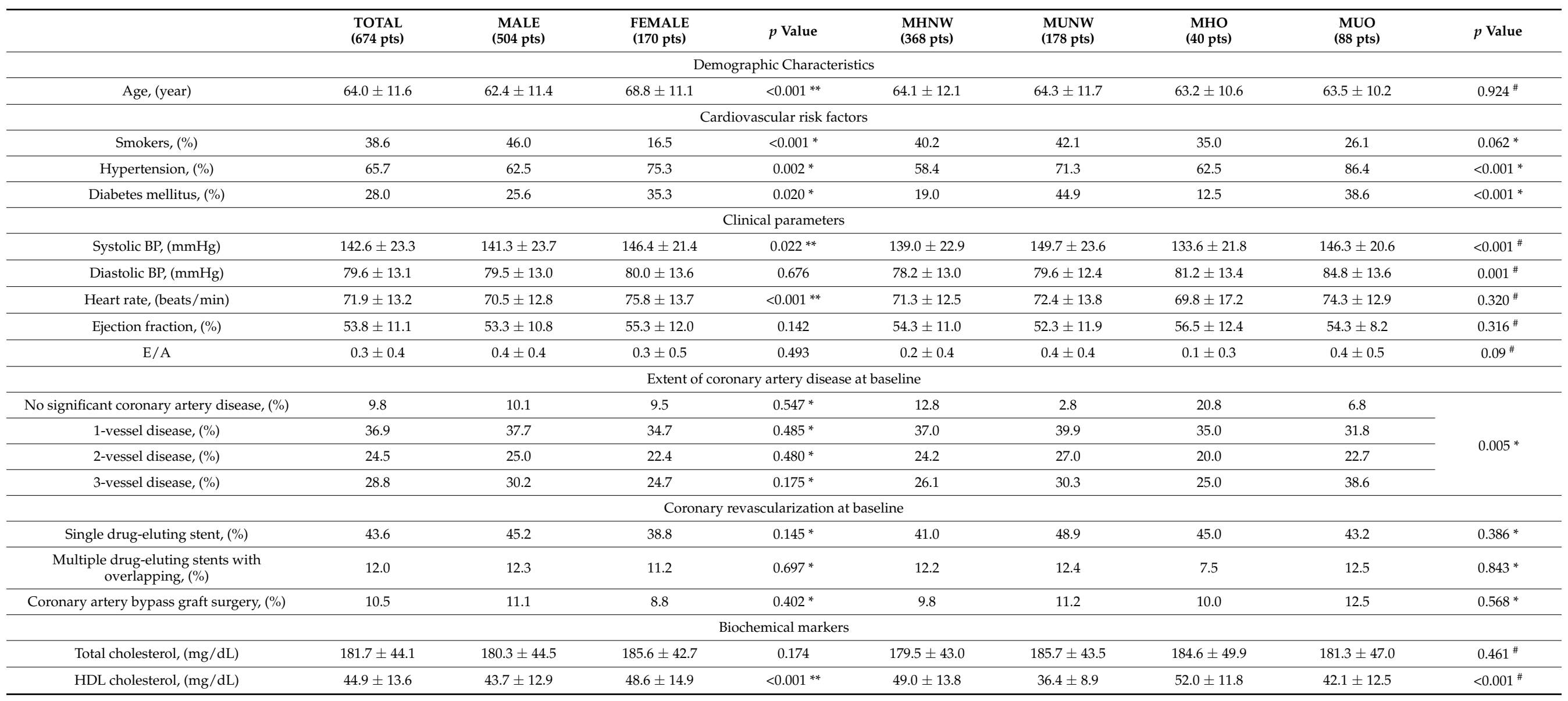


Table 1. Cont.

\begin{tabular}{|c|c|c|c|c|c|c|c|c|c|}
\hline & $\begin{array}{l}\text { TOTAL } \\
\text { (674 pts) }\end{array}$ & $\begin{array}{c}\text { MALE } \\
\text { (504 pts) }\end{array}$ & $\begin{array}{l}\text { FEMALE } \\
\text { (170 pts) }\end{array}$ & $p$ Value & $\begin{array}{l}\text { MHNW } \\
\text { (368 pts) }\end{array}$ & $\begin{array}{l}\text { MUNW } \\
\text { (178 pts) }\end{array}$ & $\begin{array}{c}\text { MHO } \\
\text { (40 pts) }\end{array}$ & $\begin{array}{l}\text { MUO } \\
\text { (88 pts) }\end{array}$ & $p$ Value \\
\hline \multicolumn{10}{|c|}{ Biochemical markers } \\
\hline LDL cholesterol, (mg/dL) & $107.0 \pm 39.6$ & $106.8 \pm 40.2$ & $107.6 \pm 37.7$ & 0.821 & $108.1 \pm 38.8$ & $107.3 \pm 40.7$ & $107.4 \pm 45.8$ & $101.3 \pm 37.6$ & $0.565^{\#}$ \\
\hline Triglyceride (mg/dL) & $146.5 \pm 90.3$ & $150.1 \pm 94.3$ & $136.3 \pm 76.8$ & 0.088 & $111.7 \pm 47.2$ & $209.3 \pm 104.9$ & $107.0 \pm 35.6$ & $181.9 \pm 123.7$ & $<0.001^{\#}$ \\
\hline Fasting glucose, $(\mathrm{mg} / \mathrm{dL})$ & $126.4 \pm 59.7$ & $123.9 \pm 56.5$ & $133.9 \pm 67.7$ & 0.058 & $114.7 \pm 59.1$ & $151.8 \pm 58.6$ & $104.4 \pm 45.0$ & $134.2 \pm 52.2$ & $<0.001^{\#}$ \\
\hline Creatinine, $(\mathrm{mg} / \mathrm{dL})$ & $1.0 \pm 0.8$ & $1.0 \pm 0.7$ & $0.9 \pm 0.8$ & 0.299 & $1.0 \pm 0.9$ & $1.0 \pm 0.8$ & $0.9 \pm 0.3$ & $0.9 \pm 0.4$ & $0.746^{\#}$ \\
\hline C-reactive protein, $(\mathrm{mg} / \mathrm{dL})$ & $10.5 \pm 21.0$ & $10.4 \pm 20.3$ & $10.8 \pm 23.6$ & 0.879 & $8.5 \pm 14.6$ & $11.4 \pm 25.2$ & $12.4 \pm 12.7$ & $15.4 \pm 30.4$ & $0.280^{\#}$ \\
\hline \multicolumn{10}{|c|}{ Medication following coronary revascularization } \\
\hline Antiplatelet therapy, $(\%)$ & 99.5 & 99.1 & 98.6 & $0.540 *$ & 99.4 & 99.6 & 99.2 & 100.0 & $0.954 *$ \\
\hline Statins, $(\%)$ & 99.3 & 97.2 & 96.2 & $0.612 *$ & 99.7 & 99.4 & 98.9 & 99.5 & $0.944 *$ \\
\hline Diuretics, (\%) & 28.3 & 27.5 & 26.4 & $0.654^{*}$ & 27.4 & 27.7 & 28.6 & 29.7 & 0.554 * \\
\hline ACE inhibitor, $(\%)$ & 97.4 & 97.2 & 96.2 & $0.167^{*}$ & 97.6 & 96.6 & 98.1 & 97.3 & $0.898^{*}$ \\
\hline Beta-blocker, $(\%)$ & 95.5 & 95.3 & 94.4 & $0.343 *$ & 95.2 & 95.1 & 96.5 & 95.3 & $0.789 *$ \\
\hline
\end{tabular}

Data are $n, \%$, mean \pm SD. pts: patients; MHNW: metabolically healthy and normal weight; MUNW: metabolically unhealthy but normal weight; MHO: metabolically healthy but obese; MUO: metabolically unhealthy and obese; ${ }^{*} p$ values are for Chi-square; ${ }^{* *} p$ values are for independent Student $t ;{ }^{*} p$ values are for ANOVA. 
Overall, metabolic abnormalities were more represented in the MUNW group, followed by the MUO phenotype. Thus, the rate of T2DM (44.9\%), SBP values $(149.7 \mathrm{mmHg}$ ), HDL-C values ( $36.4 \mathrm{mg} / \mathrm{dL})$, triglycerides $(209.3 \mathrm{mg} / \mathrm{dL}), \mathrm{FBG}(151.8 \mathrm{mg} / \mathrm{dL})$ and smoking habit $(42.1 \% ; p=0.062)$ were all significantly impaired in the MUNW subjects as compared with the other groups. The MUO phenotype was significantly associated with a higher rate of hypertension (86.4\%) and abnormal values of DBP, HDL-C, triglycerides and FBG. Conversely, smoking habit was more frequent in the MHNW group $(40.2 \% ; p=0.062)$, whereas total cholesterol and LDL-C, as well as creatinine and CRP mean levels were similar in the four groups.

The extent of coronary artery disease (CAD) also significantly differed among the obesity-related phenotypes, reflecting a gradual worsening of the disease from the metabolic healthy subjects to the unhealthy obese patients: subjects without significant CAD at baseline were more numerous in the MHO subgroup $(20.8 \%)$ and poorly represented in the MUNW subgroup (2.8\%); the highest rate of subjects with one-vessel and two-vessel diseases belonged to the MUNW group, and more than $38 \%$ of subjects of the MUO subgroup had a three-vessel disease (Table 1).

\subsection{Baseline Clinical Characteristics According to Sex-and Obesity-Related Phenotypes}

Figure 1 shows the baseline distribution of obesity-related phenotypes in men and women, separately. Among the 170 women participating in the study, $83(48.8 \%)$ were included in the MHNW subgroup, 51 (30\%) in the MUNW group, 12 (7.05\%) in the MHO subgroup and 25 (14.14\%) in the MUO subgroup. Among the 504 men, $56.5 \%$ were included in the MHNW subgroup, $25.2 \%$ in the MUNW group, $5.5 \%$ in the MHO and $12.8 \%$ in the MUO group.

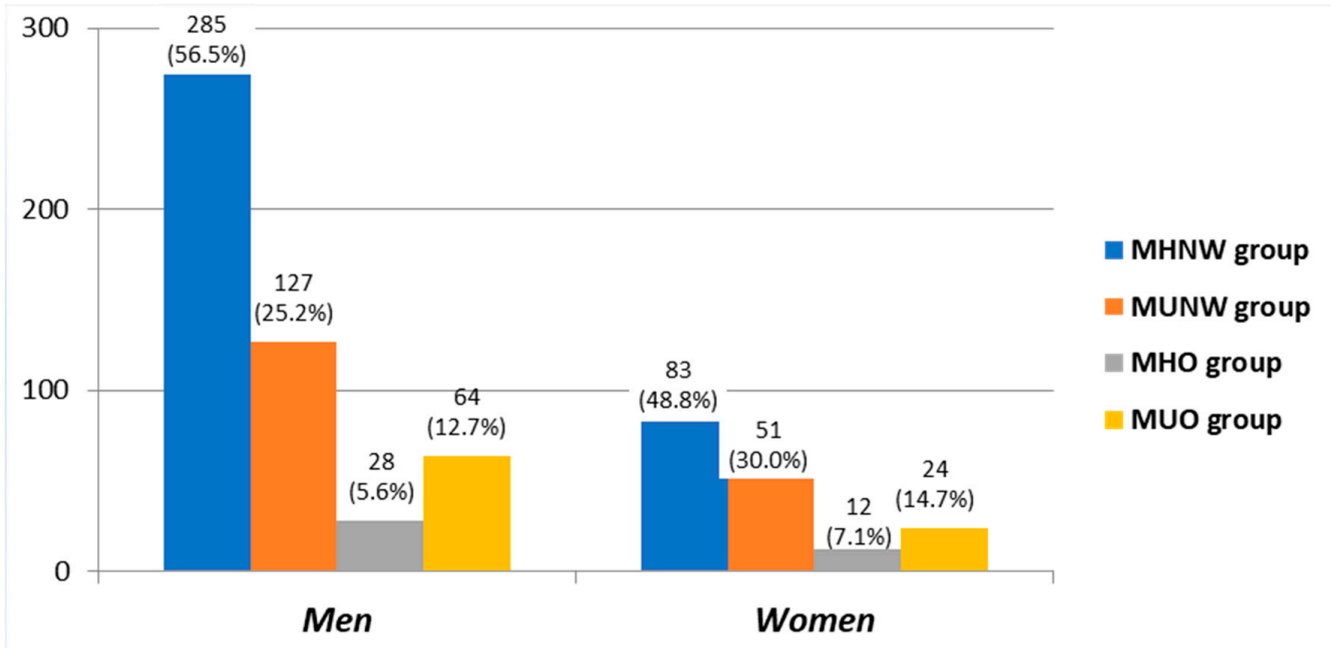

Figure 1. Baseline distribution of obesity-related phenotypes in men and women, separately. MHNW: metabolically healthy and normal weight; MUNW: metabolically unhealthy but normal weight; MHO: metabolically healthy but obese; MUO: metabolically unhealthy and obese. $p<0.001$ for ANOVA comparisons among groups, both in men and women. $p>0.05$ for Chi-square comparisons between men and women rates of obesity-related phenotypes.

Clinical characteristics according to metabolic phenotypes were analyzed separately in ACS men and women (Table 2A,B). In both genders, no significant differences were noted with regard to age, creatinine, $\mathrm{PCR}$, several echocardiographic parameters (ejection fraction and E/A), heart rate, type of coronary revascularization and pharmacological therapy across the different obesity-related phenotypes. 
Table 2. (A) Study variables at baseline according to metabolic phenotypes in men with ACS. (B) Study variables at baseline according to metabolic phenotypes in women with ACS.

\begin{tabular}{|c|c|c|c|c|c|}
\hline (A) & $\begin{array}{l}\text { MHNW } \\
\text { (285 pts) }\end{array}$ & $\begin{array}{l}\text { MUNW } \\
\text { (127 pts) }\end{array}$ & $\begin{array}{l}\text { MHO } \\
\text { (28 pts) }\end{array}$ & $\begin{array}{l}\text { MUO } \\
\text { (64 pts) }\end{array}$ & $p$ Value \\
\hline \multicolumn{6}{|l|}{ Demographic characteristics } \\
\hline Age, (year) & $62.9 \pm 11.9$ & $61.9 \pm 11.1$ & $60.9 \pm 10.7$ & $62.5 \pm 9.8$ & $0.765^{\#}$ \\
\hline \multicolumn{6}{|l|}{ Cardiovascular risk factors } \\
\hline Smokers, $(\%)$ & 46.7 & 52.1 & 46.4 & 31.3 & $0.058 *$ \\
\hline Hypertension, $(\%)$ & 55.4 & 68.5 & 53.6 & 85.9 & $<0.001 *$ \\
\hline Diabetes mellitus, $(\%)$ & 17.5 & 40.9 & 7.1 & 39.1 & $<0.001$ * \\
\hline \multicolumn{6}{|l|}{ Clinical parameters } \\
\hline Systolic BP, (mmHg) & $136.8 \pm 22.9$ & $150.6 \pm 23.9$ & $131.1 \pm 24.0$ & $146.5 \pm 19.1$ & $<0.001^{\#}$ \\
\hline Diastolic BP, (mmHg) & $77.7 \pm 12.9$ & $81.3 \pm 12.0$ & $79.1 \pm 12.9$ & $84.2 \pm 13.7$ & $0.003^{\#}$ \\
\hline Heart rate, (beats/min) & $69.9 \pm 12.0$ & $71.1 \pm 12.9$ & $69.2 \pm 18.6$ & $72.9 \pm 13.1$ & $0.511^{\#}$ \\
\hline Ejection fraction, $(\%)$ & $53.7 \pm 10.9$ & $52.5 \pm 11.7$ & $54.6 \pm 11.5$ & $53.6 \pm 7.3$ & $0.829^{\#}$ \\
\hline $\mathrm{E} / \mathrm{A}$ & $0.3 \pm 0.4$ & $0.4 \pm 0.4$ & $0.1 \pm 0.3$ & $0.4 \pm 0.5$ & $0.113^{\#}$ \\
\hline \multicolumn{6}{|l|}{$\begin{array}{l}\text { Extent of coronary artery } \\
\text { disease at baseline }\end{array}$} \\
\hline $\begin{array}{c}\text { No significant coronary artery } \\
\text { disease, }(\%)\end{array}$ & 9.5 & 1.6 & 14.3 & 4.7 & \multirow{4}{*}{0.007 * } \\
\hline 1-vessel disease, $(\%)$ & 38.6 & 37.1 & 46.4 & 31.3 & \\
\hline 2-vessel disease, $(\%)$ & 24.2 & 27.6 & 21.4 & 25.1 & \\
\hline 3-vessel disease, $(\%)$ & 27.7 & 33.9 & 17.9 & 39.1 & \\
\hline Single drug-eluting stent, (\%) & 43.5 & 46.5 & 50.1 & 48.4 & $0.817 *$ \\
\hline $\begin{array}{l}\text { Multiple drug-eluting stents } \\
\text { with overlapping, }(\%)\end{array}$ & 13.7 & 10.2 & 7.9 & 10.9 & $0.759 *$ \\
\hline $\begin{array}{c}\text { Coronary artery bypass graft } \\
\text { surgery, }(\%)\end{array}$ & 10.2 & 13.4 & 7.1 & 12.5 & $0.787^{*}$ \\
\hline \multicolumn{6}{|l|}{ Biochemical markers } \\
\hline Total cholesterol, (mg/dL) & $178.9 \pm 43.1$ & $183.9 \pm 44.7$ & $178.5 \pm 49.1$ & $180.6 \pm 48.8$ & $0.753^{\#}$ \\
\hline HDL cholesterol, (mg/dL) & $47.6 \pm 13.3$ & $35.3 \pm 8.6$ & $48.9 \pm 11.0$ & $41.2 \pm 10.0$ & $<0.001^{\#}$ \\
\hline LDL cholesterol, (mg/dL) & $108.9 \pm 39.4$ & $105.8 \pm 41.6$ & $107.7 \pm 46.6$ & $99.2 \pm 38.5$ & $0.379 \#$ \\
\hline Triglyceride (mg/dL) & $113.4 \pm 49.2$ & $217.1 \pm 104.4$ & $108.2 \pm 39.3$ & $198.1 \pm 139.2$ & $<0.001^{\#}$ \\
\hline Fasting glucose, $(\mathrm{mg} / \mathrm{dL})$ & $115.1 \pm 60.9$ & $145.8 \pm 50.8$ & $100.5 \pm 31.3$ & $130.1 \pm 40.7$ & $<0.001^{\#}$ \\
\hline Creatinine, $(\mathrm{mg} / \mathrm{dL})$ & $1.0 \pm 0.9$ & $1.0 \pm 0.7$ & $0.9 \pm 0.3$ & $1.0 \pm 0.4$ & $0.905^{\#}$ \\
\hline C-reactive protein, $(\mathrm{mg} / \mathrm{dL})$ & $9.4 \pm 15.5$ & $9.7 \pm 21.9$ & $12.4 \pm 12.7$ & $16.1 \pm 35.5$ & $0.440^{\#}$ \\
\hline \multicolumn{6}{|l|}{$\begin{array}{c}\text { Medication following } \\
\text { coronary revascularization }\end{array}$} \\
\hline Antiplatelet therapy, $(\%)$ & 98.4 & 97.6 & 97.1 & 99.9 & $0.564^{*}$ \\
\hline Statins, $(\%)$ & 99.3 & 99.1 & 97.3 & 98.8 & $0.173 *$ \\
\hline Diuretics, $(\%)$ & 28.4 & 27.9 & 29.4 & 29.1 & $0.223 *$ \\
\hline ACE inhibitor, $(\%)$ & 96.5 & 97.6 & 98.6 & 98.2 & $0.431 *$ \\
\hline Beta-blocker, $(\%)$ & 94.6 & 96.1 & 97.1 & 96.1 & 0.551 * \\
\hline
\end{tabular}


Table 2. Cont.

\begin{tabular}{|c|c|c|c|c|c|}
\hline (B) & $\begin{array}{l}\text { MHNW } \\
(83 \text { pts) }\end{array}$ & $\begin{array}{l}\text { MUNW } \\
\text { (51 pts) }\end{array}$ & $\begin{array}{l}\text { MHO } \\
(12 \text { pts) }\end{array}$ & $\begin{array}{l}\text { MUO } \\
(24 \text { pts) }\end{array}$ & $p$ Value \\
\hline \multicolumn{6}{|l|}{ Demographic characteristics } \\
\hline Age, (year) & $68.5 \pm 11.6$ & $70.4 \pm 11.1$ & $68.1 \pm 8.1$ & $11.1 \pm 10.9$ & $0.549^{\#}$ \\
\hline \multicolumn{6}{|l|}{ Cardiovascular risk factors } \\
\hline Smokers, $(\%)$ & 18.1 & 17.6 & 8.3 & 16.0 & $0.792 *$ \\
\hline Hypertension, (\%) & 68.7 & 78.4 & 83.3 & 84.1 & $0.210 *$ \\
\hline Diabetes mellitus, (\%) & 24.1 & 54.9 & 25.1 & 36.1 & $0.003 *$ \\
\hline \multicolumn{6}{|l|}{ Clinical parameters } \\
\hline Systolic BP, (mmHg) & $146.7 \pm 21.2$ & $147.5 \pm 22.8$ & $140.2 \pm 14.3$ & $146.1 \pm 23.7$ & $0.839^{\#}$ \\
\hline Diastolic BP, (mmHg) & $80.1 \pm 13.4$ & $75.5 \pm 12.4$ & $86.4 \pm 13.7$ & $86.1 \pm 13.7$ & $0.007^{\#}$ \\
\hline Heart rate, (beats/min) & $75.9 \pm 12.9$ & $75.9 \pm 15.5$ & $71.6 \pm 14.1$ & $77.1 \pm 12.4$ & $0.841^{\#}$ \\
\hline Ejection fraction, $(\%)$ & $56.9 \pm 11.4$ & $51.9 \pm 12.5$ & $63.1 \pm 15.3$ & $55.8 \pm 10.5$ & $0.191^{\#}$ \\
\hline $\mathrm{E} / \mathrm{A}$ & $0.3 \pm 0.5$ & $0.4 \pm 0.5$ & $0.3 \pm 0.4$ & $0.7 \pm 0.4$ & $0.391^{\#}$ \\
\hline \multicolumn{6}{|l|}{$\begin{array}{l}\text { Extent of coronary artery } \\
\text { disease at baseline }\end{array}$} \\
\hline $\begin{array}{l}\text { No significant coronary artery } \\
\text { disease, }(\%)\end{array}$ & 24.1 & 5.9 & 33.3 & 12.1 & \multirow{4}{*}{$0.367 *$} \\
\hline 1-vessel disease, $(\%)$ & 31.1 & 47.1 & 8.3 & 32.0 & \\
\hline 2-vessel disease, $(\%)$ & 24.1 & 25.5 & 16.7 & 20.1 & \\
\hline 3-vessel disease, $(\%)$ & 20.5 & 21.6 & 41.7 & 36.1 & \\
\hline Single drug-eluting stent, (\%) & 32.5 & 54.9 & 33.3 & 32.0 & $0.045 *$ \\
\hline $\begin{array}{l}\text { Multiple drug-eluting stents } \\
\text { with overlapping, (\%) }\end{array}$ & 7.2 & 17.6 & 0.0 & 16.1 & $0.129 *$ \\
\hline $\begin{array}{c}\text { Coronary artery bypass graft } \\
\text { surgery, }(\%)\end{array}$ & 8.4 & 5.9 & 0.0 & 12.1 & $0.603 *$ \\
\hline \multicolumn{6}{|l|}{ Biochemical markers } \\
\hline Total cholesterol, (mg/dL) & $181.6 \pm 42.6$ & $190.1 \pm 40.7$ & $199.1 \pm 50.8$ & $183.4 \pm 42.8$ & $0.476^{\#}$ \\
\hline HDL cholesterol, (mg/dL) & $54.2 \pm 14.0$ & $39.3 \pm 9.2$ & $60.3 \pm 10.1$ & $45.1 \pm 17.7$ & $<0.001^{\#}$ \\
\hline LDL cholesterol, (mg/dL) & $105.4 \pm 37.1$ & $111.2 \pm 38.5$ & $106.6 \pm 45.9$ & $107.5 \pm 35.3$ & $0.869^{\#}$ \\
\hline Triglyceride (mg/dL) & $106.1 \pm 39.4$ & $192.1 \pm 104.8$ & $104.1 \pm 26.5$ & $138.6 \pm 52.8$ & $<0.001^{\#}$ \\
\hline Fasting glucose, $(\mathrm{mg} / \mathrm{dL})$ & $113.4 \pm 53.0$ & $166.9 \pm 73.1$ & $113.6 \pm 68.1$ & $145.3 \pm 73.8$ & $<0.001^{\#}$ \\
\hline Creatinine, $(\mathrm{mg} / \mathrm{dL})$ & $0.9 \pm 0.8$ & $1.1 \pm 1.0$ & $0.8 \pm 0.1$ & $0.8 \pm 0.2$ & $0.513^{\#}$ \\
\hline C-reactive protein, (mg/dL) & $5.1 \pm 12.6$ & $16.1 \pm 33.3$ & $11.6 \pm 22.1$ & $13.9 \pm 15.8$ & $0.194^{\#}$ \\
\hline \multicolumn{6}{|l|}{$\begin{array}{l}\text { Medication following } \\
\text { coronary revascularization }\end{array}$} \\
\hline Antiplatelet therapy, (\%) & 99.3 & 96.4 & 95.9 & 98.4 & $0.453 *$ \\
\hline Statins, $(\%)$ & 98.2 & 98.4 & 97.3 & 99.3 & $0.226 *$ \\
\hline Diuretics, $(\%)$ & 30.1 & 28.6 & 28.5 & 29.6 & $0.331 *$ \\
\hline ACE inhibitor, (\%) & 97.4 & 96.4 & 97.8 & 99.4 & $0.546 *$ \\
\hline Beta-blocker, $(\%)$ & 95.9 & 97.1 & 98.2 & 97.3 & $0.662 *$ \\
\hline
\end{tabular}

(A) Data are $n, \%$, mean \pm SD. pts: patients; MHNW: metabolically healthy and normal weight; MUNW: metabolically unhealthy but normal weight; MHO: metabolically healthy but obese; MUO: metabolically unhealthy and obese; ${ }^{*} p$ values are for Chi-square; ${ }^{\#} p$ values are for ANOVA. (B) Data are $n, \%$, mean \pm SD. pts: patients, MHNW: metabolically healthy and normal weight; MUNW: metabolically unhealthy but normal weight; $\mathrm{MHO}$ metabolically healthy but obese; MUO: metabolically unhealthy and obese; ${ }^{*} p$ values are for Chi-square; ${ }^{\#} p$ values are for ANOVA.

In men (Table 2A), metabolically unhealthy individuals (MUO and MUNW) showed the worst metabolic risk factor profile, especially the MUNW subgroup (Table 2A). Thus, 
smoking habit, diabetes, SBP, low HDL-C/High triglycerides and FBG were all significantly increased in the MUNW group, whereas the rate of hypertension and DBP values were higher in the MUO group $(p<0.01$, all). Furthermore, male MUO subjects had the largest extension of CAD, with $39.1 \%$ of subjects with three-vessel disease at baseline $(p=0.007)$.

In ACS women (Table 2B), the distribution of major CVD risk factors among obesityrelated phenotypes was similar to that observed in men. Thus, diabetes, lower HDL-C and higher triglycerides values, and higher FBG were also more frequent in the MUNW group than in the others, followed by the MUO phenotype for the frequency of major risk factors. However, in women, no differences in hypertension rate, as well as in the extent of CAD according to obesity phenotypes were noted. The single drug-eluting stent procedure was also more frequent in women with MUNW $(54.9 \% ; p=0.045)$.

3.4. Cumulative Incidence of the Composite Outcome of Death, Fatal or Nonfatal Reinfarction with or without PCI and/or Stroke in ACS Patients, According to Sex and Obesity/Metabolic Phenotypes

During the 7 years of observation, 80 CVD events including 4 CVD deaths, 69 nonfatal reinfarctions and 7 nonfatal strokes occurred. Figure 2 shows the Kaplan-Meier curves for cumulative survival free from CVD events (composite primary outcome of death, fatal or nonfatal reinfarction with or without PCI and/or stroke) stratified by BMI and metabolic status combining each other as previously described. As shown, the survival curves diverged significantly (log-rank test, $p=0.006$ ) according to metabolic status rather than obesity, and this effect was more prominent in women $(p=0.047)$ than in men $(p=0.011)$.

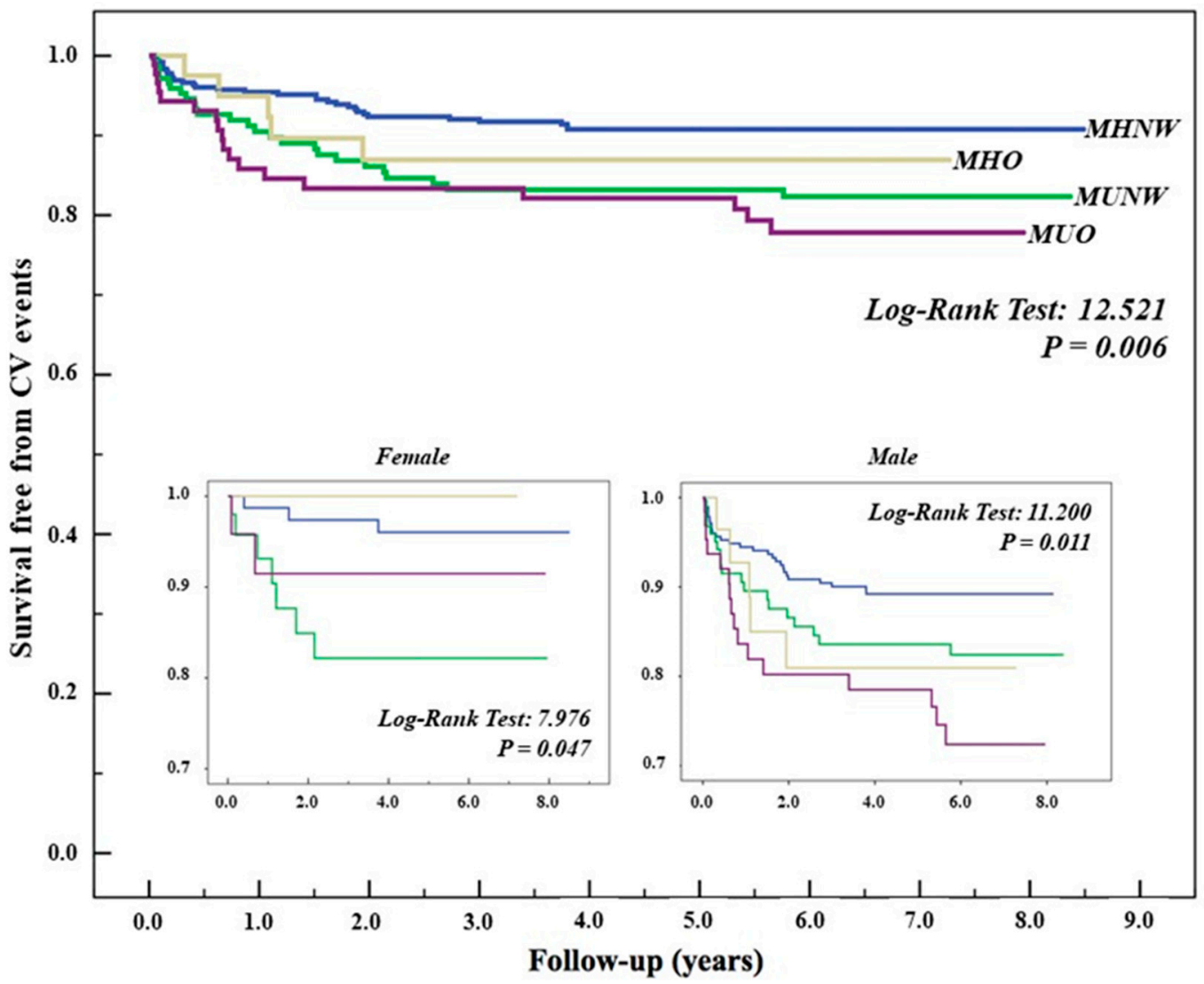

Figure 2. CVD risk according to metabolic phenotypes, overall and in men and women with ACS.

The rate of CVD events (100 person-years) was 8.4\% in the MHNW subgroup (reference group), 14.6\% in the MUNW groups, 12.5 and 20.4 in the MHO and MUO groups, respectively. The univariate risk ratio (RR) adjusted for age and sex (Table 3) was 1.86 (1.06-3.24 95\% CI) for the MUNW, 1.55 (0.56-4.25 95\% CI) for the MHO and 2.79 (1.48-5.27) for the MUO subgroup, 
with the MHNW as the reference group. However, after multivariate adjustment for age, sex, smoking and total cholesterol, the RR was higher in the MUNW subgroup (RR 2.01; $1.19-3.3895 \% \mathrm{CI})$, whereas it was $1.24(0.77-1.9995 \% \mathrm{CI})$ in the metabolic healthy obese (MHO) individuals and $1.38(1.13-1.6795 \% \mathrm{CI})$ in the metabolic unhealthy obese (MUO) subjects (Table 3 ).

Table 3. CVD recurrence according to metabolic phenotypes.

\begin{tabular}{ccccc}
\hline & MHNW & MUNW & MHO & MUO \\
\hline $\begin{array}{c}\text { Number of } \\
\text { person-years }\end{array}$ & 1951.05 & 780.95 & 207.30 & 438.87 \\
\hline $\begin{array}{c}\text { Rate of CVD } \\
\text { events (100 } \\
\text { person-years) }\end{array}$ & 8.4 & 14.6 & 12.5 & 20.4 \\
\hline $\begin{array}{c}\text { Univariate risk } \\
\text { ratio }{ }^{\text {a }} \text { (95\% CI) }\end{array}$ & 1.0 & $1.86(1.06-3.24)^{\mathrm{c}}$ & $1.55(0.56-4.25)^{\mathrm{c}}$ & $2.79(1.48-5.27)^{\mathrm{c}}$ \\
\hline $\begin{array}{c}\text { Multivariate risk } \\
\text { ratio }{ }^{\mathrm{b}} \text { (95\% CI) }\end{array}$ & 1.0 & $2.01(1.19-3.38)^{\mathrm{c}}$ & $1.24(0.77-1.99)^{\mathrm{c}}$ & $1.38(1.13-1.67)^{\mathrm{c}}$ \\
\hline${ }^{\mathrm{a}}$ Adjusted for age and sex. ${ }^{\mathrm{b}}$ Adjusted for age, sex, smoking and total cholesterol. ${ }^{\mathrm{c}}$ Matched with MHNW population.
\end{tabular}

The overall rate of CVD events (100 person-years) in the reference group (MHNW) was higher in men than in women (1.19 vs. 0.6$)$, and it progressively increased across the obesity-related phenotypes (8.3 in the MUO group), but this trend was not observed in women (Table 4A,B).

Table 4. (A) CVD recurrence according to metabolic phenotypes in men with ACS. (B) CVD recurrence according to metabolic phenotypes in women with ACS.

\begin{tabular}{|c|c|c|c|c|}
\hline (A) & MHNW & MUNW & MHO & MUO \\
\hline Number of person-years & 1471.39 & 574.39 & 132.35 & 299.16 \\
\hline $\begin{array}{l}\text { Rate of CVD events } \\
\text { (100 person-years) }\end{array}$ & 1.9 & 3.3 & 3.7 & 8.3 \\
\hline Univariate risk ratio $(95 \% \mathrm{CI})$ & 1.0 & $1.17(0.66-2.08)^{\mathrm{c}}$ & $1.45(0.52-3.88)^{\mathrm{C}}$ & $2.4(1.01-1.33)^{\mathrm{c}}$ \\
\hline Multivariate risk ratio a $(95 \% \mathrm{CI})$ & 1.0 & $1.11(0.71-1.98)^{\mathrm{c}}$ & $1.39(0.61-3.11)^{c}$ & $2.2(1.11-1.54)^{\mathrm{c}}$ \\
\hline (B) & MHNW & MUNW & MHO & MUO \\
\hline Number of person-years & 479.66 & 206.56 & 74.94 & 139.90 \\
\hline $\begin{array}{l}\text { Rate of CVD events } \\
\text { (100 person-years) }\end{array}$ & 0.6 & 3.4 & 0.0 & 2.1 \\
\hline Univariate risk ratio $(95 \% \mathrm{CI})$ & 1.0 & $3.6(1.09-12.03)^{c}$ & $0.9(0.88-0.96)^{\mathrm{c}}$ & $2.1(0.51-8.21)^{\mathrm{c}}$ \\
\hline Multivariate risk ratio ${ }^{\mathrm{b}}(95 \% \mathrm{CI})$ & 1.0 & $3.2(1.23-9.98)$ & 0.0 & $1.8(0.49-7.44)^{\mathrm{c}}$ \\
\hline
\end{tabular}

(A) a Adjusted for age, smoking and total cholesterol. ${ }^{\mathrm{c}}$ Matched with MHNW population. $(\mathbf{B})^{\mathrm{b}}$ Adjusted for age, smoking and total cholesterol. ${ }^{\mathrm{C}}$ Matched with MHNW population.

As shown in Table 3 and in Figure 2, in the combined analysis, the overall risk of the composite primary outcome was highest in the MUO group (RR 2.79; IC: 1.48-5.27) with the univariate analysis, whereas, after multiple adjustment, the MUNW group showed the highest risk (RR: 2.01; IC: 1.19-3.38). A divergent trend was noted when this analysis was repeated in ACS male and female patients separately.

Thus, in men (Table 4A, Figure 2), the MUO group showed the highest RR both with the univariate (RR: 2.4; IC: 1.1-1.33) and multivariate analysis (RR: 2.2; IC: 1.1-1.54), followed by the MHO phenotype (RR: 1.39); conversely, in women, the MHO phenotype showed the lowest whereas the MUNW group showed the highest risk (RR: 1.8). 
3.5. Factors Associated with the Incidence of the Composite Outcome of Death, Fatal or Nonfatal Reinfarction with or without PCI and/or Stroke in ACS Men and Women

Table 5 shows the factors significantly associated with the risk of CVD recurrence. In men, age, BMI, and HDL-C concentration were all significantly associated with the primary outcome, whereas these independent associations were not observed in ACS women.

Table 5. Factors associated with CVD recurrence in men and women.

\begin{tabular}{ccccccc}
\hline & $\begin{array}{c}\text { TOTAL } \\
\text { Exp(B) }\end{array}$ & $p$ Value * & $\begin{array}{c}\text { Male } \\
\operatorname{Exp(B)}\end{array}$ & $p$ Value * & $\begin{array}{c}\text { Female } \\
\text { Exp(B) }\end{array}$ & $p$ Value * \\
\hline Male sex & 0.524 & 0.425 & - & & - & \\
\hline Age & 1.054 & 0.119 & 1.102 & 0.019 & 0.566 & 0.997 \\
\hline BMI & 1.216 & 0.022 & 1.251 & 0.038 & 1.169 & 0.667 \\
\hline Systolic Blood Pressure & 0.973 & 0.122 & 0.958 & 0.141 & 0.777 & 0.563 \\
\hline Diastolic Blood Pressure & 1.049 & 0.113 & 1.044 & 0.179 & 1.322 & 0.543 \\
\hline Heart rate & 0.975 & 0.207 & 0.954 & 0.061 & 0.877 & 0.876 \\
\hline Ejection fraction & 1.022 & 0.465 & 1.061 & 0.116 & 1.121 & 0.121 \\
\hline E/A & 2.266 & 0.145 & 1.397 & 0.609 & 1.875 & 0.512 \\
\hline Total Cholesterol & 1.015 & 0.369 & 1.020 & 0.269 & 0.987 & 0.867 \\
\hline HDL Cholesterol & 0.973 & 0.332 & 0.905 & 0.023 & 0.676 & 0.771 \\
\hline LDL Cholesterol & 0.983 & 0.313 & 0.982 & 0.330 & 0.232 & 0.911 \\
\hline Triglycerides & 1.002 & 0.088 & 1.002 & 0.128 & 0.991 & 0.879 \\
\hline Fasting glucose & 0.998 & 0.720 & 0.987 & 0.076 & 1.02 & 0.783 \\
\hline Creatinine & 0.368 & 0.295 & 0.345 & 0.285 & 0.451 & 0.913 \\
\hline C reactive protein & 1.000 & 0.978 & 1.007 & 0.614 & 0.999 & 0.985 \\
\hline${ }^{*} p$ values are for Logistic regression analysis. & & & & &
\end{tabular}

\section{Discussion}

Obesity affects millions of men and women worldwide, and BMI is linearly associated with CVD morbidity and mortality in both genders [2,17-21].

However, the role of different obese/metabolic phenotypes on the CVD risk in specific high-risk populations is still debated. Moreover, the effect of sex-gender differences has seldom been taken into account. Here, we demonstrated a different impact of obesity/metabolic phenotypes on long-term CVD outcomes in men and women presenting with ACS.

Literature data reported better mortality outcomes in overweight or mildly obese patients with CVD, with an unexpected association between a higher BMI and survival that has been termed the "obesity paradox" [22].

Although all the reasons behind this paradox have not been fully clarified yet, they probably comprise the increasingly recognized "metabolically healthy obese" (MHO) phenotype, which includes obese patients without metabolic abnormalities typically associated with obesity.

In this study, we analyzed the predictive role of different obesity-related phenotypes, including obese subjects without MetS (MHO) and normal-weight patients with MetS (MUNW) on long-term CVD outcomes in a very high risk population, such as subjects hospitalized for ACS. In our cohort, the prevalence of MHO (5.9\%) was similar in men and women, and comparable with that reported in other cohorts with different CVD risks [23-25]. Conversely, normal-weight subjects represented the vast majority of our ACS patients, with the MHNW group being the most represented group (54.6\%), followed by the MUNW group (26.4\%). In this setting, we identified a stronger impact of metabolic profile than the degree of obesity on the composite CVD outcome of death, fatal or nonfatal 
reinfarction with or without $\mathrm{PCI}$ and/or stroke, the risk being significantly higher in the metabolically unhealthy groups (MUO and MUNW).

In accordance with our findings, several epidemiological studies have demonstrated a lower morbidity and mortality risk in MHO subjects when compared to MUO individuals, suggesting that cardiometabolic risk factors have a stronger impact than obesity per se on the CVD risk [23-27].

However, several lines of evidence indicate that MHO subjects may not be fully protected from a CVD risk, including heart failure [28]. An increased CVD risk in MHO individuals was also reported in the San Antonio Heart Study [6], and in several systematic reviews and meta-analyses, showing that $\mathrm{MHO}$ is not a benign condition, and the degree of the associated risk may vary according to the length of follow-up and the adopted therapeutic/preventive strategies [29-33].

Accordingly, a meta-analysis of 14 prospective studies [32] reported a higher $>15$-year CVD risk in both MHO (pooled RR 2.00; 95\% CI 1.79-2.24) and MUNW individuals (RR $1.81 ; 95 \%$ CI 1.56-2.10) compared to normal-weight subjects.

These data suggest a crucial role of the length of follow-up in interpreting the risk associated with the $\mathrm{MHO}$ phenotype, and our data collected during a 7-year follow-up confirm the results of other long-term studies. Accordingly, it has been recently demonstrated that MHO subjects would change their phenotype over time. In this regard, the MESA study (Multi-Ethnic Study of Atherosclerosis) demonstrated that almost half of the participants would develop MetS during the follow-up over $>12$ years, and subjects with this "unstable" MHO phenotype would have a linear increase of the risk according to the length of the exposure to metabolic abnormalities [34]. Moreover, Fingeret et al. also recently reported that in a group of $179 \mathrm{MHO}$ subjects, less than 50\% remained MHO during follow-up, whereas the majority of subjects developed MetS factors [35].

When we analyzed the distribution of metabolic risk factors across BMI phenotypes in our study population, we found that the MUNW group carried the highest burden of risk factors, followed by the MUO subjects, as it was partly expected according to the study design, grouping patients by BMI and MetS status.

Notably, the burden of T2DM was particularly high in the MHNW group, especially in men. In spite of the potential effect of the reduction of the sample size in each subgroup after stratification by sex and phenotypes, it is likely that in nonobese subjects, glucose metabolism derangement may be the major factor for developing ACS.

There is a complex relationship among insulin resistance, obesity and inflammation, in which inflammatory molecules and microRNAs (miRs) expression play an incisive role. Indeed, obese subjects overexpress inflammatory cytokines and oxidative stress markers, which could negatively affect the cardiac performance; some microRNAs (miRs) are key regulatory factors in lipid formation and lipoprotein synthesis and changes in microRNA profiles of various tissues correlate with obesity and MetS.

In women with and without T2DM, inflammatory markers correlated with more atherogenic lipid profiles, including specific HDL subpopulations [36]. Furthermore, it has been recently reported that obese subjects with prediabetes overexpressed inflammatory/oxidative stress molecules, miR-195 and miR-27, when compared to obese normoglycemic patients [37], suggesting that the relationship between obesity and inflammation may be particularly dangerous in subjects with altered glucose homeostasis.

It has also to be noted that fasting blood glucose levels were overall high in all the examined subgroups. This may be related to an underlying T2DM, but also to "stress hyperglycemia", which may have an enormous impact on outcomes in patients hospitalized for ACS. Thus, the role of high glucose levels in determining CVD outcomes in ACS subjects is well demonstrated and a tight glycemic control has been described as affecting cardiac remodeling and CVD outcomes in ACS patients [38,39].

The risk category of the enrolled population is another important issue to be considered. ACS is a critical manifestation of CAD, carrying a high mortality and disability 
burden. MetS is associated with ACS in young patients ( $<45$ years), where obesity is the most prevalent risk factor [40,41].

Studies on the role of obesity-related phenotypes in ACS patients are still limited [42,43].

Overall, obese patients with ACS appear to have more favorable short-term outcomes, although the benefits seem to disappear over time. Thus, in the MERLIN-TIMI 36 trial, on over 6000 ACS patients, those with BMI $>30 \mathrm{~kg} / \mathrm{m}^{2}$ had a significant lower risk of the primary endpoint at 30 days, whereas no difference according to BMI was observed at 1 year [9]. A similar short-term benefit was observed in the BARI registry [44], whereas no differences according to BMI were observed in the short-term outcomes (30 days) of subjects with an overall lower baseline CVD risk, presenting to the emergency units with ACS-like symptoms [8].

In patients enrolled in our study, who underwent a baseline coronary revascularization for ACS, our results point to the predominant role of the metabolic milieu vs. obesity per se in the definition of the long-term CVD risk. Our findings are consistent with other large-scale studies indicating that metabolically healthy individuals, either with or without obesity, have a lower CVD risk than those with MetS [23-25], although not all the studies are concordant $[6,30]$.

The type of outcome and/or potential age and sex differences may also contribute to explain the inconsistent results in the literature. Thus, a recent meta-analysis confirmed a higher risk for CVD and all-cause mortality among MHO individuals, with a significant effect of age and sex [45]. As for age, a nationwide analysis showed that overweight and obese elderly patients had a lower risk of mortality, CVD events and procedure-related complications [46].

In the hospitalized geriatric population participating to the REPOSI study, specific sex-aging phenotypes showed different mortality outcomes, with middle-aged men with multimorbidity and older women with severe cognitive decline being at higher risk [47].

In our study, women with ACS were older (68.8 vs. 62.4 years) and had more MetS risk factors than men; in this population we showed that the risk of CV events according to obesity-related phenotypes is also profoundly influenced by sex.

It is now widely recognized that the risk of CVD events is profoundly different in men and women, due to multiple and multifaceted factors [48].

CVD risk factors may have a different burden in men and women, as reported for T2DM $[49,50]$. Moreover, obesity differently impacts men and women worldwide, because of genetic, ethnical, hormonal and social-related aspects [51], with clinical implications for the CVD risk. Thus, several studies have documented that obesity is significantly associated with the CVD risk in both men and women [9,42], but sex differences in morbidity and mortality have been reported in specific populations [52].

In particular, body characteristics and specific localization of fat deposition could influence the CVD risk in women, and the mammary gland has been reported to be a specific target for fat accumulation in premenopausal women. Indeed, in a large population of women aged $>40$ years in premenopause, a greater distribution of mammary fat and a lower breast density affected the incidence of MACEs at the 10-year follow-up [53].

Furthermore, it has been reported that the obesity paradox, i.e., the potential beneficial effect of the MHO phenotype on the CVD risk, seems to be more evident in women than in men [5-7]. In Swedish men, an increased CVD risk associated with MHO status has been demonstrated [5], whereas in the San Antonio Heart Study, the risk of developing CVD was found to be increased in $\mathrm{MHO}$, regardless of sex [6].

In our study, we identified sex differences in the CVD risk associated with different obesity-related phenotypes, with obesity appearing to be a significant risk factor for the composite outcome in men but not in women. Among females, MHO participants had the least risk with no reported events, whereas women with the unhealthy phenotype (MUNW and MUO) showed a higher risk, irrespective of BMI; the opposite was true for obese men, since both obesity phenotypes (MHO and MUO) were at higher risk. 
Thus, our data demonstrated that the "overweight paradox" was more evident in ACS women than in men, since $\mathrm{MHO}$ women were the most protected against major events over a long follow-up, as also reported in other studies [14,54].

Several aspects merit considerations for the interpretation of our results. Women hospitalized for ACS were older, more obese and with an overall higher risk factors burden, including T2DM, when compared to men.

The older age in ACS women is an expected finding because of the 10 -year gap in the CVD risk due to estrogen effects during the reproductive age [51]. Furthermore, the larger prevalence of T2DM among women confirm the well-known greater impact of T2DM on the CVD risk in women than in men $[55,56]$. Thus, in women included in our study, it is likely that T2DM had a greater burden on the CVD risk than obesity per se.

Similarly, a Portuguese registry reported that obesity, hypertension, diabetes, and dyslipidemia were all more prevalent among women admitted for ACS between 2002 and 2019, who were also less likely to present with typical symptoms and to be treated according to guidelines, thus exposing them to worst in-hospital outcomes and a higher mortality [57].

Further examining the differences between men and women in our population, the CVD risk was overall higher in men than in women, and men had a larger extension of CAD, with significant differences according to obesity/metabolic phenotypes.

Conversely, our data do not confirm the gender gap in cardiovascular treatments, that has been reported in other studies [58], since the rate of revascularization procedures as well as the use of drugs with CVD benefit were comparable between the two genders.

Moreover, although obesity may induce a variety of structural and functional alterations in the myocardium, with some sex differences $[59,60]$, no differences in EF\% as well as in other echocardiographic parameters were observed between men and women in our study.

Several potential limitations should also be acknowledged in our study. First, the observational nature of the study may have prevented us from excluding all potential confounders and to detect cause-effect relationships. Moreover, the classification of obesity, that was mainly based on BMI, since the waist-to-hip ratio was collected approximately in two thirds of the population, has to be taken into account. In addition, the low number of women included in the study compared with men, which reflects the real-world gender distribution in patients hospitalized for ACS, may have influenced the CVD event rate in some subgroups.

Information on several gender-related variables, such as the socioeconomic status, physical activity and nutrition were also not available, as well as $\mathrm{HbA1c}$ and fasting insulin levels, which could have been important to elucidate the role of insulin resistance and T2DM diagnosis and control on CVD outcomes, especially in women. Finally, the risk for indication bias could not be fully ruled out, due to the recruitment carried out in only two centers.

\section{Conclusions}

In conclusion, our data show a sex-specific impact of obesity phenotypes on the longterm CVD and mortality risks in patients hospitalized for ACS. Thus, while MHO women seemed to be protected over time, in men, obesity had a stronger impact irrespective of metabolic status. These data emphasize the importance of assessing metabolic status and implementing systematic metabolic surveillance in patients undergoing coronary revascularization procedures, even if their weight is normal. If confirmed, this hypothesis may offer an attractive pathophysiological basis for the different CV risks observed in obese individuals, with important consequences on their personalized clinical management.

Author Contributions: E.I. and G.T.R. analyzed and interpreted the data and wrote the manuscript; E.I. and M.V. performed the analysis; V.A.C., A.G., A.S., L.O., V.R., M.P., A.F.G.C., A.G.V., P.D.M. and G.D. contributed to writing the manuscript; G.S. and M.V. critically read and revised the manuscript. All authors have read and agreed to the published version of the manuscript. 
Funding: This research received no external funding.

Institutional Review Board Statement: This research obtained a positive evaluation from the local ethics committee.

Informed Consent Statement: Written informed consent has been obtained from the patients to publish this paper.

Data Availability Statement: The datasets used and/or analyzed during the current study are available from the corresponding author on reasonable request.

Conflicts of Interest: The authors declare no conflict of interest.

\section{References}

1. Steg, P.G.; James, S.K.; Atar, D.; Badano, L.P.; Lundqvist, C.B.; Borger, M.A.; Di Mario, C.; Dickstein, K.; Ducrocq, G.; FernandezAviles, F.; et al. ESC Guidelines for the management of acute myocardial infarction in patients presenting with ST-segment elevation. Eur. Heart J. 2012, 33, 2569-2619. [CrossRef] [PubMed]

2. Mancia, G.; Fagard, R.; Narkiewicz, K.; Redon, J.; Zanchetti, A.; Böhm, M.; Christiaens, T.; Cífková, R.; De Backer, G.; Dominiczak, A.; et al. 2013 ESH/ESC Practice Guidelines for the Management of Arterial Hypertension. Blood Press. 2013, 23, 3-16. [CrossRef] [PubMed]

3. Schiller, N.B.; Shah, P.M.; Crawford, M.; DeMaria, A.; Devereux, R.; Feigenbaum, H.; Gutgesell, H.; Reichek, N.; Sahn, D.; Schnittger, I.; et al. Recommendations for quantitation of the left ventricle by two-dimensional echocardiography. American Society of Echocardiography Committee on standards, subcommittee on quantitation of two-dimensional echocardiograms. $J$. Am. Soc. Echocardiogr. 1989, 2, 358-367. [CrossRef]

4. Greenland, S. Modeling and variable selection in epidemiologic analysis. Am. J. Public Health 1989, 79, 340-349. [CrossRef] [PubMed]

5. Arnlöv, J.; Ingelsson, E.; Sundström, J.; Lind, L. Impact of body mass index and the metabolic syndrome on the risk of cardiovascular disease and death in middle-aged men. Circulation 2010, 121, 230-236.

6. Aung, K.; Lorenzo, C.; Hinojosa, M.A.; Haffner, S.M. Risk of Developing Diabetes and Cardiovascular Disease in Metabolically Unhealthy Normal-Weight and Metabolically Healthy Obese Individuals. J. Clin. Endocrinol. Metab. 2014, 99, 462-468. [CrossRef] [PubMed]

7. Opio, J.; Croker, E.; Odongo, G.S.; Attia, J.; Wynne, K.; McEvoy, M. Metabolically healthy overweight/obesity are associated with increased risk of cardiovascular disease in adults, even in the absence of metabolic risk factors: A systematic review and meta-analysis of prospective cohort studies. Obes. Rev. 2020, 21, e13127. [CrossRef] [PubMed]

8. Dooley, J.; Chang, A.M.; Salhi, R.A.; Hollander, J.E. Relationship between body mass index and prognosis of patients presenting with potential acute coronary syndromes. Acad. Emerg. Med. 2013, 20, 904-910. [CrossRef] [PubMed]

9. Kadakia, M.B.; Fox, C.S.; Scirica, B.M.; Murphy, S.A.; Bonaca, M.P.; Morrow, D.A. Central obesity and cardiovascular outcomes in patients with acute coronary syndrome: Observations from the MERLIN-TIMI 36 trial. Heart 2011, 97, 1782-1787. [CrossRef]

10. Xu, J.-J.; Song, Y.; Jiang, P.; Jiang, L.; Zhao, X.-Y.; Gao, Z.; Li, J.-X.; Qiao, S.-B.; Gao, R.-L.; Yang, Y.-J.; et al. Effects of metabolic syndrome on onset age and long-term outcomes in patients with acute coronary syndrome. World J. Emerg. Med. 2021, 12, 36-41. [CrossRef]

11. Heymsfield, S.B.; Peterson, C.M.; Thomas, D.M.; Heo, M.; Schuna, J.M. Why are there race/ethnic differences in adult body mass index-adiposity relationships? A quantitative critical review. Obes. Rev. 2015, 17, 262-275. [CrossRef] [PubMed]

12. Garawi, F.; Devries, K.; Thorogood, N.; Uauy, R. Global differences between women and men in the prevalence of obesity: Is there an association with gender inequality? Eur. J. Clin. Nutr. 2014, 68, 1101-1106. [CrossRef] [PubMed]

13. Kouvari, M.; Chrysohoou, C.; Dilaveris, P.; Georgiopoulos, G.; Magkas, N.; Aggelopoulos, P.; Panagiotakos, D.B.; Tousoulis, D. Skeletal muscle mass in acute coronary syndrome prognosis: Gender-based analysis from Hellenic Heart Failure cohort. Nutr. Metab. Cardiovasc. Dis. 2019, 29, 718-727. [CrossRef]

14. Kouvari, M.; Chrysohoou, C.; Tsiamis, E.; Kosyfa, H.; Kalogirou, L.; Filippou, A.; Iosifidis, S.; Aggelopoulos, P.; Pitsavos, C.; Tousoulis, D. The "overweight paradox" in the prognosis of acute coronary syndrome for patients with heart failure-A truth for all? A 10-year follow-up study. Maturitas 2017, 102, 6-12. [CrossRef] [PubMed]

15. Goossens, G.H. The Metabolic Phenotype in Obesity: Fat Mass, Body Fat Distribution, and Adipose Tissue Function. Obes. Facts 2017, 10, 207-215. [CrossRef] [PubMed]

16. Grundy, S.M.; Cleeman, J.I.; Daniels, S.R.; Donato, K.A.; Eckel, R.H.; Franklin, B.A.; Gordon, D.J.; Krauss, R.M.; Savage, P.J.; Smith, S.C., Jr.; et al. Diagnosis and management of the metabolic syndrome: An American Heart Association/National Heart, Lung, and Blood Institute scientific statement. Circulation 2005, 112, 2735-2752. [CrossRef] [PubMed]

17. Wilkins, K.; Campbell, N.R.; Joffres, M.R.; McAlister, F.A.; Nichol, M.; Quach, S.; Johansen, H.L.; Tremblay, M.S. Blood pressure in Canadian adults. Health Rep. 2010, 21, 37-46.

18. Poirier, P.; Giles, T.D.; Bray, G.A.; Hong, Y.; Stern, J.S.; Pi-Sunyer, F.X.; Eckel, R.H. Obesity and cardiovascular disease: Pathophysiology, evaluation, and effect of weight loss: An update of the 1997 American Heart Association Scientific Statement on Obesity and Heart Disease from the Obesity Committee of the Council on Nutrition, Physical Activity, and Metabolism. Circulation 2006, $113,898-918$. 
19. The Emerging Risk Factors Collaboration Separate and combined associations of body-mass index and abdominal adiposity with cardiovascular disease: Collaborative analysis of 58 prospective studies. Lancet 2011, 377, 1085-1095. [CrossRef]

20. Poirier, P.; Giles, T.D.; Bray, G.A.; Hong, Y.; Stern, J.S.; Pi-Sunyer, F.X.; Eckel, R.H. Obesity and Cardiovascular Disease. Arter. Thromb. Vasc. Biol. 2006, 26, 968-976. [CrossRef]

21. Poirier, P.; Eckel, R.H. Obesity and cardiovascular disease. Curr. Atheroscler. Rep. 2002, 4, 448-453. [CrossRef] [PubMed]

22. Romero-Corral, A.; Montori, V.; Somers, V.K.; Korinek, J.; Thomas, R.; Allison, T.G.; Mookadam, F.; Lopez-Jimenez, F. Association of bodyweight with total mortality and with cardiovascular events in coronary artery disease: A systematic review of cohort studies. Lancet 2006, 368, 666-678. [CrossRef]

23. Appleton, S.L.; Seaborn, C.J.; Visvanathan, R.; Hill, C.L.; Gill, T.K.; Taylor, A.W.; Adams, R.J.; North West Adelaide Health Study Team. Diabetes and cardiovascular disease outcomes in the metabolically healthy obese phenotype: A cohort study. Diabetes Care 2013, 36, 2388-2394. [CrossRef]

24. Hamer, M.; Stamatakis, E. Metabolically Healthy Obesity and Risk of All-Cause and Cardiovascular Disease Mortality. J. Clin. Endocrinol. Metab. 2012, 97, 2482-2488. [CrossRef]

25. Voulgari, C.; Tentolouris, N.; Dilaveris, P.; Tousoulis, D.; Katsilambros, N.; Stefanadis, C. Increased heart failure risk in normalweight people with metabolic syndrome compared with metabolically healthy obese individuals. J. Am. Coll. Cardiol. 2011, 58, 1343-1350. [CrossRef] [PubMed]

26. Calori, G.; Lattuada, G.; Piemonti, L.; Garancini, M.P.; Ragogna, F.; Villa, M.; Mannino, S.; Crosignani, P.; Bosi, E.; Luzi, L.; et al. Prevalence, metabolic features, and prognosis of metabolically healthy obese Italian individuals: The Cremona Study. Diabetes Care 2011, 34, 210-215. [CrossRef]

27. Choi, K.M.; Cho, H.J.; Choi, H.Y.; Yang, S.J.; Yoo, H.J.; Seo, J.A.; Kim, S.G.; Baik, S.H.; Choi, D.S.; Kim, N.H. Higher mortality in metabolically obese normal-weight people than in metabolically healthy obese subjects in elderly Koreans. Clin. Endocrinol. 2013, 79, 364-370. [CrossRef] [PubMed]

28. Mørkedal, B.; Vatten, L.J.; Romundstad, P.R.; Laugsand, L.E.; Janszky, I. Risk of Myocardial Infarction and Heart Failure Among Metabolically Healthy But Obese Individuals. J. Am. Coll. Cardiol. 2014, 63, 1071-1078. [CrossRef] [PubMed]

29. Roberson, L.L.; Aneni, E.C.; Maziak, W.; Agatston, A.S.; Feldman, T.; Rouseff, M.; Tran, T.; Blaha, M.J.; Santos, R.D.; Sposito, A.C.; et al. Beyond BMI: The "Metabolically healthy obese" phenotype \& its association with clinical/subclinical cardiovascular disease and all-cause mortality-A systematic review. BMC Public Health 2014, 14, 14. [CrossRef]

30. Kramer, C.K.; Zinman, B.; Retnakaran, R. Are Metabolically Healthy Overweight and Obesity Benign Conditions?: A Systematic Review and Meta-Analysis. Ann. Intern. Med. 2013, 159, 758. [CrossRef] [PubMed]

31. Eckel, N.; Meidtner, K.; Kalle-Uhlmann, T.; Stefan, N.; Schulze, M.B. Metabolically healthy obesity and cardiovascular events: A systematic review and meta-analysis. Eur. J. Prev. Cardiol. 2015, 23, 956-966. [CrossRef] [PubMed]

32. Fan, J.; Song, Y.; Chen, Y.; Hui, R.; Zhang, W. Combined effect of obesity and cardio-metabolic abnormality on the risk of cardiovascular disease: A meta-analysis of prospective cohort studies. Int. J. Cardiol. 2013, 168, 4761-4768. [CrossRef]

33. Zheng, R.; Zhou, D.; Zhu, Y. The long-term prognosis of cardiovascular disease and all-cause mortality for metabolically healthy obesity: A systematic review and meta-analysis. J. Epidemiol. Community Health 2016, 70, 1024-1031. [CrossRef] [PubMed]

34. Mongraw-Chaffin, M.; Foster, M.C.; Anderson, C.A.; Burke, G.L.; Haq, N.; Kalyani, R.R.; Ouyang, P.; Sibley, C.T.; Tracy, R.; Woodward, M.; et al. Metabolically Healthy Obesity, Transition to Metabolic Syndrome, and Cardiovascular Risk. J. Am. Coll. Cardiol. 2018, 71, 1857-1865. [CrossRef]

35. Fingeret, M.; Marques-Vidal, P.; Vollenweider, P. Incidence of type 2 diabetes, hypertension, and dyslipidemia in metabolically healthy obese and non-obese. Nutr. Metab. Cardiovasc. Dis. 2018, 28, 1036-1044. [CrossRef]

36. Russo, G.T.; Giandalia, A.; Romeo, E.L.; Alibrandi, A.; Horvath, K.V.; Asztalos, B.F.; Cucinotta, D. Markers of Systemic Inflammation and Apo-AI Containing HDL Subpopulations in Women with and without Diabetes. Int. J. Endocrinol. 2014, 2014, 607924. [CrossRef] [PubMed]

37. Sardu, C.; Trotta, M.C.; Pieretti, G.; Gatta, G.; Ferraro, G.; Nicoletti, G.F.; Onofrio, N.D.; Balestrieri, M.L.; Amico, M.D.; Abbatecola A.; et al. MicroRNAs modulation and clinical outcomes at 1 year of follow-up in obese patients with pre-diabetes treated with metformin vs. placebo. Geol. Rundsch. 2021, 58, 1381-1393. [CrossRef]

38. Sasso, F.C.; Rinaldi, L.; Lascar, N.; Marrone, A.; Pafundi, P.C.; Adinolfi, L.E.; Marfella, R. Role of Tight Glycemic Control during Acute Coronary Syndrome on CV Outcome in Type 2 Diabetes. J. Diabetes Res. 2018, 2018, 3106056. [CrossRef]

39. Marfella, R.; Sasso, F.C.; Cacciapuoti, F.; Portoghese, M.; Rizzo, M.R.; Siniscalchi, M.; Carbonara, O.; Ferraraccio, F.; Torella, M.; Petrella, A.; et al. Tight Glycemic Control May Increase Regenerative Potential of Myocardium during Acute Infarction. J. Clin. Endocrinol. Metab. 2012, 97, 933-942. [CrossRef]

40. Kalantzi, K.; Korantzopoulos, P.; Tzimas, P.; Katsouras, C.S.; Goudevenos, J.A.; Milionis, H.J. The relative value of metabolic syndrome and cardiovascular risk score estimates in premature acute coronary syndromes. Am. Heart J. 2008, 155, 534-540. [CrossRef]

41. Mirza, A.J.; Taha, A.Y.; Khdhir, B.R. Risk factors for acute coronary syndrome in patients below the age of 40 years. Egypt. Heart J. 2018, 70, 233-235. [CrossRef]

42. Rabkin, S.W.; Mathewson, F.A.; Hsu, P.-H. Relation of body weight to development of ischemic heart disease in a cohort of young north American men after a 26 year observation period: The manitoba study. Am. J. Cardiol. 1977, 39, 452-458. [CrossRef]

43. Hubert, H.B.; Feinleib, M.; McNamara, P.M.; Castelli, W.P. Obesity as an independent risk factor for cardiovascular disease: A 26-year follow-up of participants in the Framingham Heart Study. Circulation 1983, 67, 968-977. [CrossRef] [PubMed] 
44. Gurm, H.S.; Whitlow, P.L.; Kip, K.E. The impact of body mass index on short- and long-term outcomes inpatients undergoing coronary revascularization. Insights from the bypass angioplasty revascularization investigation (BARI). J. Am. Coll. Cardiol. 2002, 39, 834-840. [CrossRef]

45. Yeh, T.-L.; Chen, H.-H.; Tsai, S.-Y.; Lin, C.-Y.; Liu, S.-J.; Chien, K.-L. The Relationship between Metabolically Healthy Obesity and the Risk of Cardiovascular Disease: A Systematic Review and Meta-Analysis. J. Clin. Med. 2019, 8, 1228. [CrossRef] [PubMed]

46. El Moheb, M.; Jia, Z.; Qin, H.; El Hechi, M.W.; Nordestgaard, A.T.; Lee, J.M.; Han, K.; Kaafarani, H.M. The Obesity Paradox in Elderly Patients Undergoing Emergency Surgery: A Nationwide Analysis. J. Surg. Res. 2021, 265, 195-203. [CrossRef] [PubMed]

47. Marcucci, M.; Franchi, C.; Nobili, A.; Mannucci, P.M.; Ardoino, I.; REPOSI Investigators. Defining Aging Phenotypes and Related Outcomes: Clues to Recognize Frailty in Hospitalized Older Patients. J. Gerontol. Ser. A Boil. Sci. Med. Sci. 2017, 72, 395-402. [CrossRef] [PubMed]

48. Sardu, C.; Paolisso, G.; Marfella, R. Impact of Sex Differences in Incident and Recurrent Coronary Events and All-Cause Mortality. J. Am. Coll. Cardiol. 2021, 77, 829-830. [CrossRef]

49. Giandalia, A.; Alibrandi, A.; Giorgianni, L.; Piano, F.L.; Consolo, F.; Elia, G.L.; Asztalos, B.; Cucinotta, D.; Squadrito, G.; Russo, G.T. Resistin levels and inflammatory and endothelial dysfunction markers in obese postmenopausal women with type 2 diabetes mellitus. Diabetol. Metab. Syndr. 2021, 13, 98. [CrossRef]

50. Giandalia, A.; Giuffrida, A.; Gembillo, G.; Cucinotta, D.; Squadrito, G.; Santoro, D.; Russo, G. Gender Differences in Diabetic Kidney Disease: Focus on Hormonal, Genetic and Clinical Factors. Int. J. Mol. Sci. 2021, 22, 5808. [CrossRef]

51. Kautzky-Willer, A.; Handisurya, A. Metabolic diseases and associated complications: Sex and gender matter! Eur. J. Clin. Investig. 2009, 39, 631-648. [CrossRef] [PubMed]

52. Huebschmann, A.G.; Huxley, R.; Kohrt, W.M.; Zeitler, P.; Regensteiner, J.G.; Reusch, J.E.B. Sex differences in the burden of type 2 diabetes and cardiovascular risk across the life course. Diabetologia 2019, 62, 1761-1772. [CrossRef] [PubMed]

53. Sardu, C.; Gatta, G.; Pieretti, G.; Viola, L.; Sacra, C.; Di Grezia, G.; Musto, L.; Minelli, S.; La Forgia, D.; Capodieci, M.; et al. Pre-Menopausal Breast Fat Density Might Predict MACE During 10 Years of Follow-up. JACC Cardiovasc. Imaging 2020, 14, 426-438. [CrossRef] [PubMed]

54. Hioki, H.; Miura, T.; Motoki, H.; Kobayashi, H.; Kobayashi, M.; Nakajima, H.; Sekimura, N.; Mawatari, E.; Akanuma, H.; Sato, T.; et al. Lean body mass index prognostic value for cardiovascular events in patients with coronary artery disease. Heart Asia 2015, 7, 12-18. [CrossRef]

55. Peters, S.; Huxley, R.R.; Woodward, M. Diabetes as risk factor for incident coronary heart disease in women compared with men: A systematic review and meta-analysis of 64 cohorts including 858,507 individuals and 28,203 coronary events. Diabetologia 2014, 57, 1542-1551. [CrossRef]

56. Wang, Y.; O’Neil, A.; Jiao, Y.; Wang, L.; Huang, J.; Lan, Y.; Zhu, Y.; Yu, C. Sex differences in the association between diabetes and risk of cardiovascular disease, cancer, and all-cause and cause-specific mortality: A systematic review and meta-analysis of 5,162,654 participants. BMC Med. 2019, 17, 136. [CrossRef]

57. Roque, D.; Ferreira, J.; Monteiro, S.; Costa, M.; Gil, V. Understanding a woman's heart: Lessons from 14,177 women with acute coronary syndrome. Rev. Port. Cardiol. 2020, 39, 57-72. [CrossRef]

58. Hao, Y.; Liu, J.; Liu, J.; Yang, N.; Smith, S.C., Jr.; Huo, Y.; Fonarow, G.C.; Ge, J.; Taubert, K.A.; Morgan, L.; et al. Sex Differences in In-Hospital Management and Outcomes of Patients With Acute Coronary Syndrome. Circulation 2019, 139, 1776-1785. [CrossRef]

59. Poirier, P.; Martin, J.; Marceau, P.; Biron, S.; Marceau, S. Impact of bariatric surgery on cardiac structure, function and clinical manifestations in morbid obesity. Expert Rev. Cardiovasc. Ther. 2004, 2, 193-201. [CrossRef]

60. Kenchaiah, S.; Evans, J.C.; Levy, D.; Wilson, P.W.; Benjamin, E.; Larson, M.; Kannel, W.B.; Vasan, R.S. Obesity and the Risk of Heart Failure. N. Engl. J. Med. 2002, 347, 305-313. [CrossRef] 